\title{
Emergency Air Rescue System in Romania
}

\author{
Sebastian Tranca1 ${ }^{\star}$, Robert Szabo², Cătălin Dache ${ }^{3}$, Mihai Mureșan³ \\ 1. "Iuliu Hatieganu" University of Medicine and Pharmacy, Cluj-Napoca, Romania \\ 2. Emergency County Clinical Hospital Cluj-Napoca, Romania \\ 3. The General Aviation Inspectorate of the Ministry of Internal Affairs, Romania
}

The helicopter, as a means of transport, has facilitated a significant decrease in intervention time at the site of request, increasing the chances of survival of the critical patient. Since 2003, SMURD has managed to form a fleet composed of nine helicopters and two airplanes. From an operational and strategic point of view, the SMURD intervention unit, set up seven Aeromedical Operational Bases (A.O.B.) equipped with helicopters and materials necessary for their operation. There is a dynamic increase in the number of air rescue missions in Romania, with most missions being carried out by the air rescue bases in Târgu Mureș and Bucharest. Specialty literature has clearly demonstrated the positive impact on the survival of critical patients assisted by airborne crews, so it is necessary for the Romanian air rescue system to grow up. It is necessary to increase the number of air bases, purchase new helicopters and to continue the training programs of both pilots and medical personnel.

Keywords: emergency medical service, helicopter, air rescue, retrieval medicine, critical care transport

Received 12 January 2018 / Accepted 08 February 2018

Helicopter emergency medical service (HEMS) has become a significant component of prehospital treatment of traumatized patients in many countries $[1,2]$. Since its introduction into the civilian rescue system, the effects of HEMS towards time and cost efficiency has been discussed controversially $[1,3-5]$. In this context, some potential disadvantages of HEMS (e.g. high financial burden [6], availability of HEMS due to weather conditions) have been reported $[1,3,7]$. However, HEMS also seems to provide several presumable advantages compared to ground emergency medical services (GEMS). Firstly, HEMS is expected to facilitate rapid and wide ranged transport due to increased transportation velocity [8]. Secondly, HEMS medical crew members are supposed to be more experienced in trauma management improving preclinical treatment of traumatized patients [8-10].

SMURD (Mobile Emergency Service, Reanimation and Extrication Service) is a public intervention unit, integrated, without jurisdiction, of great strategic importance for Romania [11].

Air rescue is an aircraft equipped in accordance with the legal provisions in force for emergency aero-medical interventions to rescue critically ill patients requiring rapid and high-level intervention. A critical patient is defined as having unstable vital functions or with conditions that may have irreversible complications requiring special investigation, intervention and / or special care provided by a complex, multidisciplinary team in a general or specialized intensive care clinic or department.

Airborne transfer is used when a suitable transfer cannot be secured by land, or if the transfer time on the terrestrial route is longer than the condition of the patient permits, causing worsening or irreversible complications. The traumatized or non-traumatized patient, unstable or with a high potential for worsening during transport, requiring inter-hospital transfer to a specialized facility, should benefit from an optimal transport mode to ensure safe and timely delivery.

The use of aviation for humanitarian purposes was formally implemented following the Geneva Red Cross Convention in 1925. In Romania this was introduced in the Decree of Organization and Operation of the Central Civil Aviation Service of 1929, according to which, civilian aviation tasks also included air and medical transport.

Thus, in 1935, on the territory of Romania a donation from the Bucharest City Hall to the civil aviation, consisting of a medical plane, was the first structure of this kind. This aircraft was exclusively used for aero-medical missions in Romania and was the first of its kind.

The transportation of the wounded was carried out during the war by the squadron, proved that the suitably equipped aircraft is one of the most effective mean of rescuing human lives. These aspects lead to the development of sanitary aviation in Romania, therefore on 14th of November 1946 the first Aviasan sanitary aviation unit in the country was established. This aviation unit was directly subordinated to the Ministry of Health of that period.

In September of 1990, an Emergency System named SMUR was established in Targu-Mures and later after collaboration with the Fire Brigade (operational part of the service for the decommissioning) became the current SMURD which is a mobile emergency, rescue and extrication unit. Over time, beside the usual missions performed with specialized ambulances, this organization saw the need and importance of using the air transport for shortening the reaction and transport time of patients in need of medical intervention, so it started to rent aircrafts from private operators. These aircrafts were helicopters or planes 
of various types, belonging to the Ministry of the Interior, the Ministry of National Defense or to the Utility Aviation from the Ministry of Transportation. These aircrafts were also used to transport critical patients from Targu-Mures to other medical centers in Bucharest or abroad. In such situations, the medical crew consisted of two medical professionals, one of whom was a physician with experience in the field of emergency medicine or intensive care.

Since 1999, SMURD has permanently rented an IAR316B (Alouette III) helicopter from the Utility Aviation of the the Ministry of Transportation [11]. The helicopter was based at the Targu-Mures County Clinical Hospital and was equipped with the necessary equipment for resuscitation and accident interventions. The medical staff on board had an emergency physician or an anesthesia and intensive care specialist. This helicopter carried out approximately 20 to 30 flying hours a month, initially serving Mures County and later extending its services to neighboring counties.

In 2003, the current SMURD form of air-medical interventions was born, a strong organization that exceeded the SMAR project by far. Through the initiative of SMURDMures, directed by Dr. Raed Arafat, in 2003 the foundations were laid for a national helicopter emergency medical assistance system.

A major factor that determined the increase of the efficiency of SMURD operations, was the development of the air-lift department. The helicopter, as a mean of transport, has contributed to a significant decrease in reaction time at the place of request, increasing the chances of survival.

The year of 2003 represents the start of the SMURD cooperation with the Special Aviation Unit of the Ministry of Interior. The context in which this collaboration began was, first and foremost, linked to the major shortcomings represented by the need for SMURD to hire helicopters from private operators. It all culminated in the first recorded aviation accident for SMURD. In 2003, a IAR-316B type helicopter rented from Transgaz (a private company from Medias) crashed in Cojocna, Cluj County with 4 people on board. On impact, all personnel (pilot, co-pilot and SMURD medical crew consisting of a physician and nurse) were fatally injured. The Romanian helicopter used for this mission was an old model used by Aviasan in the 1970s. The cause of the tragedy was unfavorable meteorological conditions (fog, night, ice) and human factor (spatial disorientation).

During the same year, financed from the state budget, SMURD succeeded in acquiring the first Eurocopter EC-135 helicopter. Later that year, a second helicopter, the same model, was purchased by the Government. In order to keep the operating costs at a minimum, taking into account all the favorable factors presented, the Special Aviation Unit of the Ministry of the Internal Affairs was asigned to operate both helicopters and all other future aircrafts of SMURD.
Since 2003, SMURD has managed to form a fleet of nine helicopters and two airplanes. From an operational point of view the SMURD organization established seven operational bases equipped with helicopters and equipment necessary for their operation (the eighth Aeromedical Operational Base is to be opened in Jibou, Salaj County).

Since 2008, the Special Aviation Unit has been transformed into the General Inspectorate of Aviation (G.I.o.A.) of the Ministry of Internal Affairs. G.I.o.A. is the air operator that performs independent SMURD missions.

The Aeromedical Detachment from the G.I.o.A. is responsible for the operation of SMURD aircrafts. This department of the G.I.o.A. runs all the Aeromedical Operational Bases in the country.

The fleet of the Aeromedical Detachment is composed of ten aircrafts with military registrations and one with civil registration. From these eleven SMURD aircrafts, eight are EC-135, one is H 135 and two airplanes: a Piper PA 42 (turboprop) - Cheyenne and a Cessna Citation V TurboJet ( Figure1).

From the operational point of view, since 2014 the G.I.o.A. is a part of a joint organization called the Emergency Situations Department (D.S.U. in Romanian abbreviation / E.S.D.). The Emergency Situations Department is subordinated both to the Ministry of Internal Affairs and to the Ministry of Health.

The Aeromedical Detachment, component of the G.I.o.A, has subordinated operational flight structures specifically designed for intervention, search-rescue and sanitary transport called Aeromedical Operational Bases (P.O.B.).

Aeromedical Operation Bases and aircraft serving these structures are:

- Bucharest Aeromedical Operational Base Base, equipped with a helicopter type EC-135 (registration: $334)$ and two airplanes. A Piper PA-42 Cheyenne (registered: 1121) and a Cessna Citation V type Turbo-Jet (registered YR-SMD).

- The Aeromedical Operational Point Targu-Mures, which has a helicopter type EC-135 (registration 340). It operates from the Targu-Mures Aeromedical Operational Base platform located within the County Emergency Clinical Hospital in Targu-Mures. The aircraft is parked in the SMURD hangar located in the same location.

- The Iasi Aeromedical Operational Base, which has a helicopter type EC-135 (registration -342). It operates from a platform within Iasi International Airport, located in the Iasi Special Aviation Unit. The aircraft is hangered in the Iasi Aeroclub facility.

- The Arad Aeromedical Operational Base, which has a helicopter type EC-135 (registration 341). It operates within the Arad International Airport. It is parked in the hangar of Arad Aeroclub.

- The Craiova Aeromedical Operational Base, which has a helicopter type EC-135 (registration 344). It operates from the SMURD platform at Craiova International Air- 


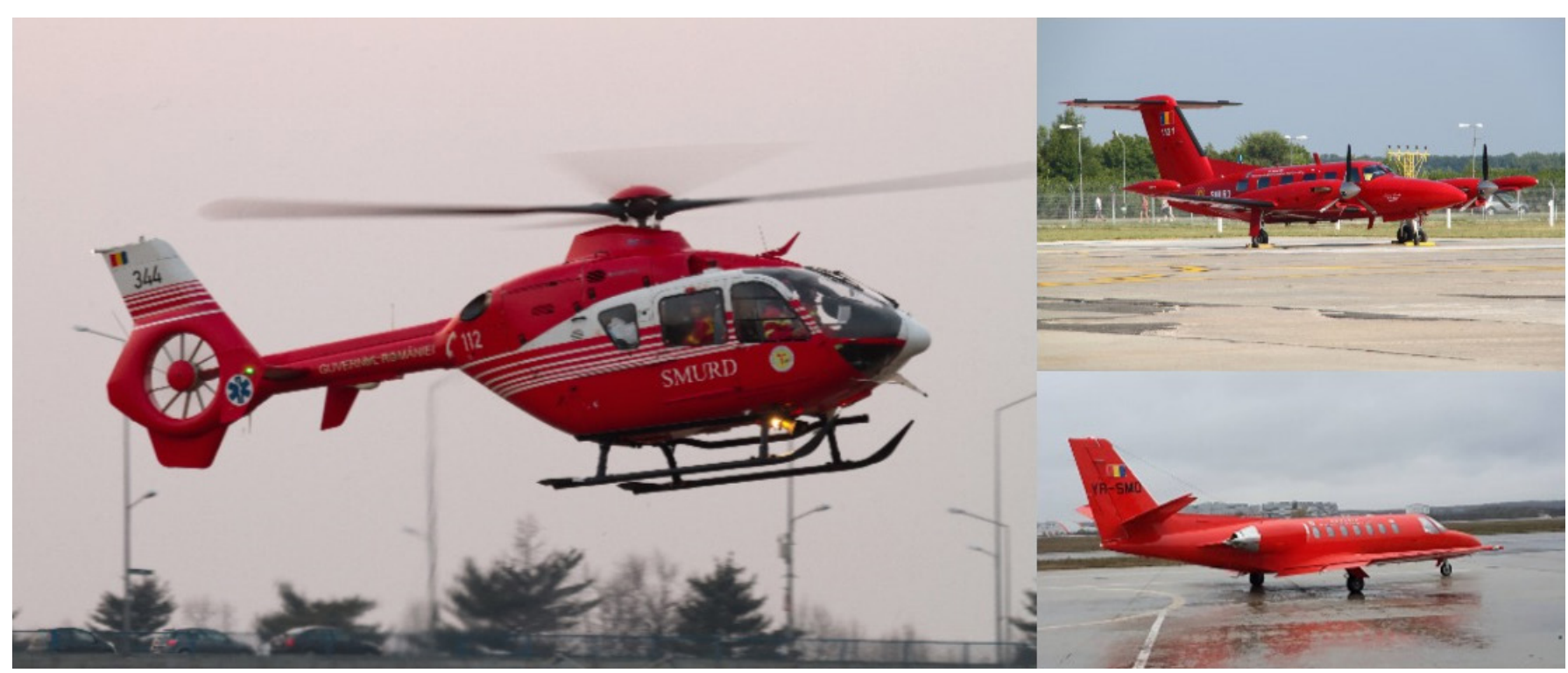

Fig. 1. Aircrafts of the SMURD organization, at left is the Airbushelicopters $\mathrm{H}-135$ helicopter, at the top-right is the Piper PA-42 Cheyenne, and the Cessna Citation V is at bottom-right.

port. The parking of the aircraft is made in the SMURD hangar located in the same location.

- The Constanta Aeromedical Operational Base, which has a helicopter type H 135 (registration 349 ). It operates from the platform of a trading company near Constanta County Emergency Clinical Hospital. The parking is in the special hangar on the outskirts of Constanta.

- Galaţi Aeromedical Operational Base, which has a helicopter type EC-135 (registration 346). It operates from the platform of the Border Police in Galati. The aircraft is parked at the Pegas Aeroclub in Galati. The SMURD hangar is going to be built until the end of the year of 2017.

- The Jibou Aeromedical Operational Base will be equipped with the registered 345 EC-135 helicopter, which will operate from the platform of the Jibou Fire Unit (Salaj County). At this location a hangar and spaces for the proper conduct of the activity were built. This Aeromedical Operational Base is not yet operational.

The distribution of the aircraft on the territorial structures (P.O.A. and S.S.A.V.) can be seen on the figure 2, each being represented by the G.I.o.A on the map of Romania.

The SMURD helicopters are equipped according to Order no. 1.092 of September 7, 2006, regarding the determination of competence and attributions of intervention teams on different levels in the pre-hospital phase, issued by the Ministry of Health. These are equipped with medical devices that provide critical patients with a high performance mechanical ventilator, difficult intubation tools, defibrillator - external cardiac stimulator, rapid infusion systems, trauma immobilization devices, suction, thoracic drain kits, central vascular catheterization kits, cricotiroidotomy kits, specialized medication, blood gas and acidbase balance analyzer, amputation kit, burn kit and an incubator for neonatal transport missions (Figure 3).

The missions carried out by the SMURD organization within the Aeromedical Department of the G.I.o.A. are di- vided into three categories: primary missions, secondary missions and special missions.

- Primary missions: are the missions carried out in the event of serious accidents in which a person urgently needs medical assistance due to injuries suffered or due to the circumstances. The methodological norms of the Government Emergency Ordinance no. 126/2003 regarding the operations define as primary missions the following:

(a) serious road accidents and other accidents in which one or more people are at vital risk due to the injuries suffered or the circumstances in which they occurred;

b) critically ill patients in small or rural settlements, in inaccessible localities or places, and in places lacking qualified emergency medical assistance for the case in question; (Figure 4). Rapid procedures are preferred to sustained on-scene treatment, particularly when surrounding conditions are hostile. HEMS emergency physicians attempt to keep on-site intervals short, treatment and monitoring to minimize delay in rescue [12]. HEMS should be used more often in case of trauma in order to guarantee the proven benefit for multiple traumatised patients [13]. The combination of the transfer by HEMS and treatment in a level I trauma center has a significantly positive effect on the survival rate of the patient, especially in patients with traumatic brain injury (TBI) [14].

c) critically ill, injured, intoxicated or other acute illnesses transported by ambulances or other means of transport to sanitary units or hospitals that cannot provide the necessary stabilization and emergency care for the respective cases, with the need for emergency transfer to specialized medical centers.

(d) patients suffering from acute conditions with a high potential for aggravation in the absence of other appropriate means of intervention nearby or likely to succumb faster than the helicopter;

e) intervention in support of the emergency and firstaid crews of the public or private emergency medical care 


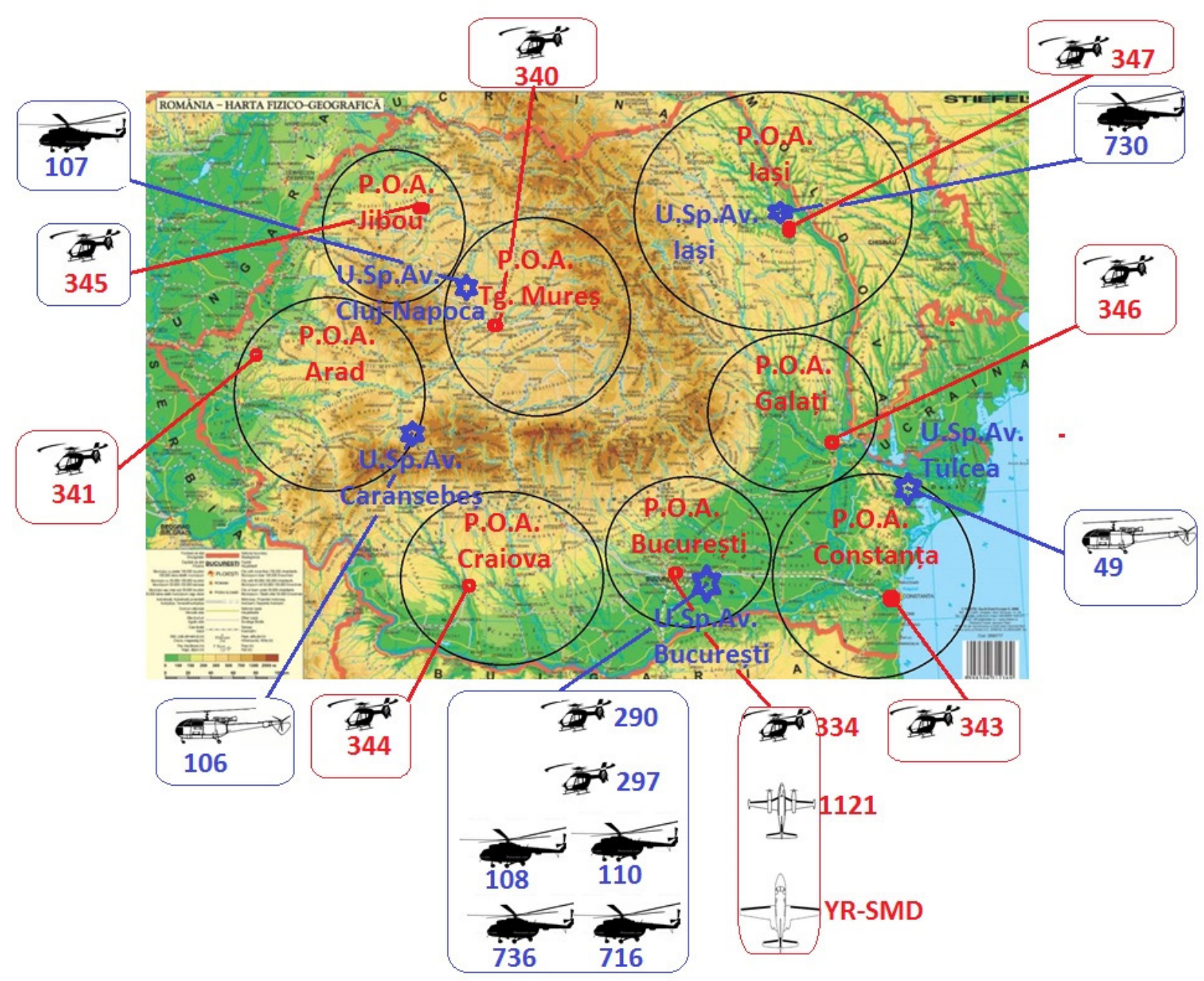

Fig. 2. Distribution of the operational structures of the G.I.o.A. on the map of Romania

services or other authorized public services upon their request (Figure 5)

Secondary missions: are the transfer missions of patients from health care units that cannot provide the appropriate investigation or medical care, requiring an emergency transfer to a specialized health facility. Currently large, and increasing, numbers of critically ill patients require transfer between critical care units [15]. Inter-unit transfer poses significant risks to critically ill patients, particularly those requiring multiple organ support. Documentation of the patient's condition, the investigations and their results, the medication administered, with the specification of the doses and hours of administration, the specialized consultations, etc. are copied and sent to the hospital receiving the patient.

Special missions are considered: Transport missions of transplant, organs for transplant and search and rescue mission.

The way of requesting the intervention of a SMURD aircraft is made exclusively by calling the 112 emergency service.

The medical crew of the helicopter includes 2-3 members, of which at least one physician. Only the following categories of doctors may serve on the helicopter: a) Emergency medicine specialists, certified for helicopter activity;

b) Specialists in anesthesia and intensive care accredited / certified for helicopter intervention;

c) Resident doctors in emergency medicine or anesthesia and intensive care, 3rd, 4th and 5th year, with the approval from the director of the helicopter medical institution and from the chief officer of the Aeromedical Operation Base and only after accreditation or attestation for helicopter intervention .

Following the tragic fire that took place on the night of 30/31 October 2015 at COLECTIV Night Club, which resulted in the death of 63 people and more than 150 injured, the Aeromedical Detachment aircraft performed 7 missions to transport seriously injured patients to hospitals abroad. Thus, between 7 and 30 November 2015, 7 flight missions were carried out, 2 by PYPE Cheyenne Pa42 in Vienna and Graz (Austria) and 5 by Cessna Citation V in Zurich (Switzerland), Vienna (2 missions) and Graz (Austria) and Le Bourget - Paris (France).

During 2015, the implementation of the cross-border project "Improving the Response Capacity of the Mobile Emergency Service for Resuscitation and Extrication (SMURD) through the joint integration of systems 


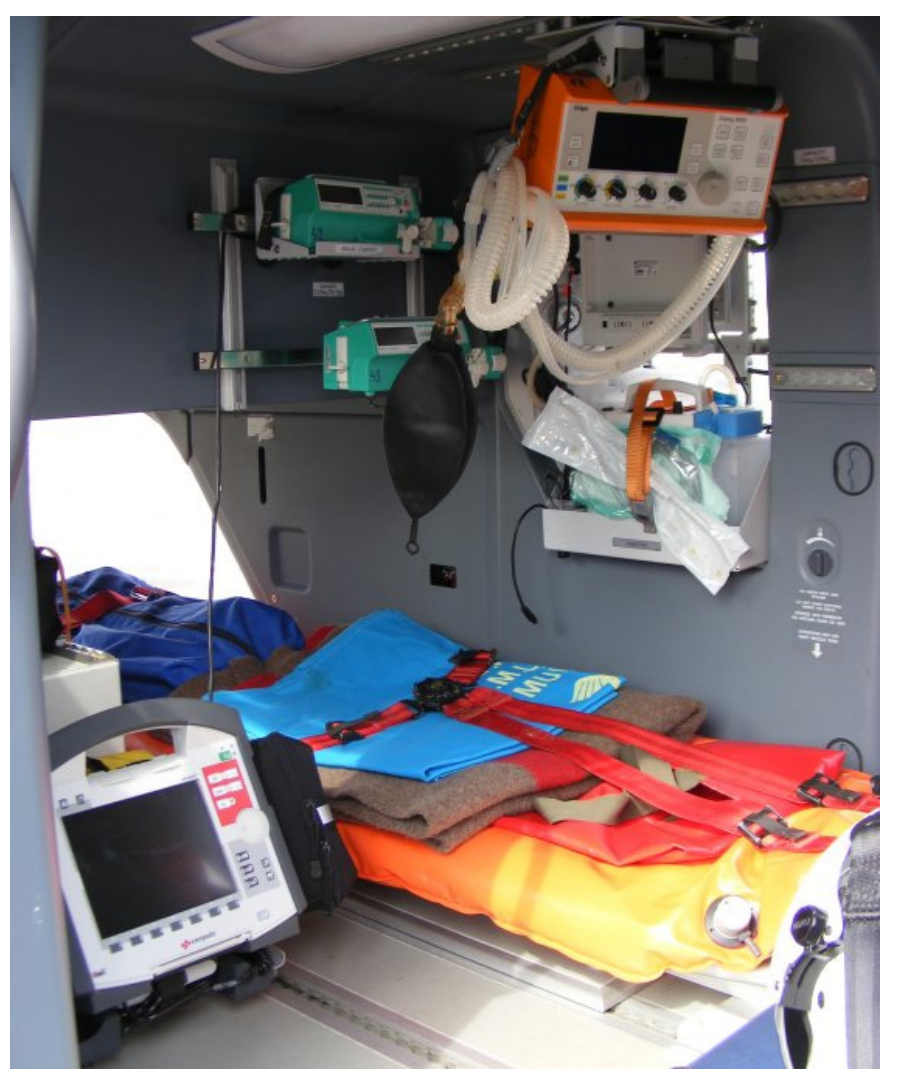

Fig. 3. The inside of a SMURD helicopter

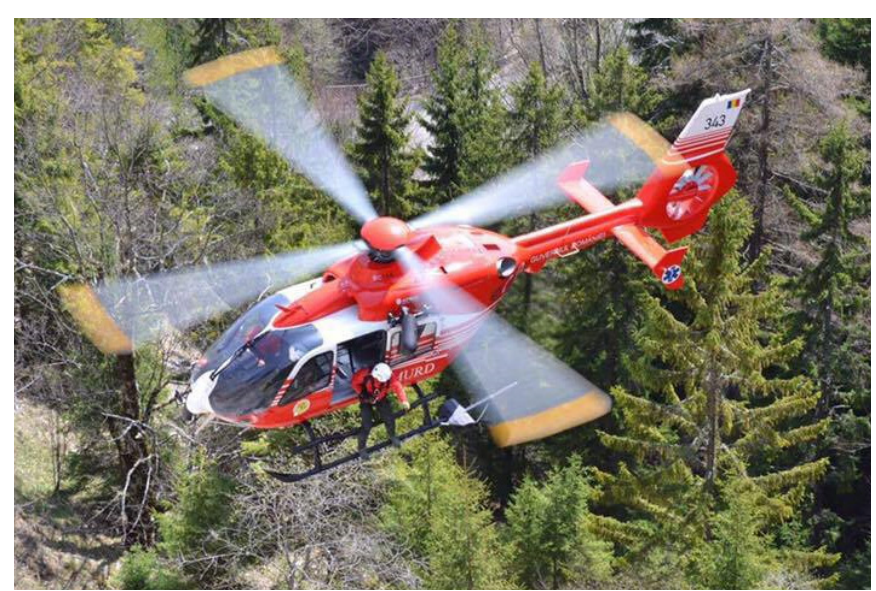

Fig. 4. Helicopter intervention in hard-to-reach areas

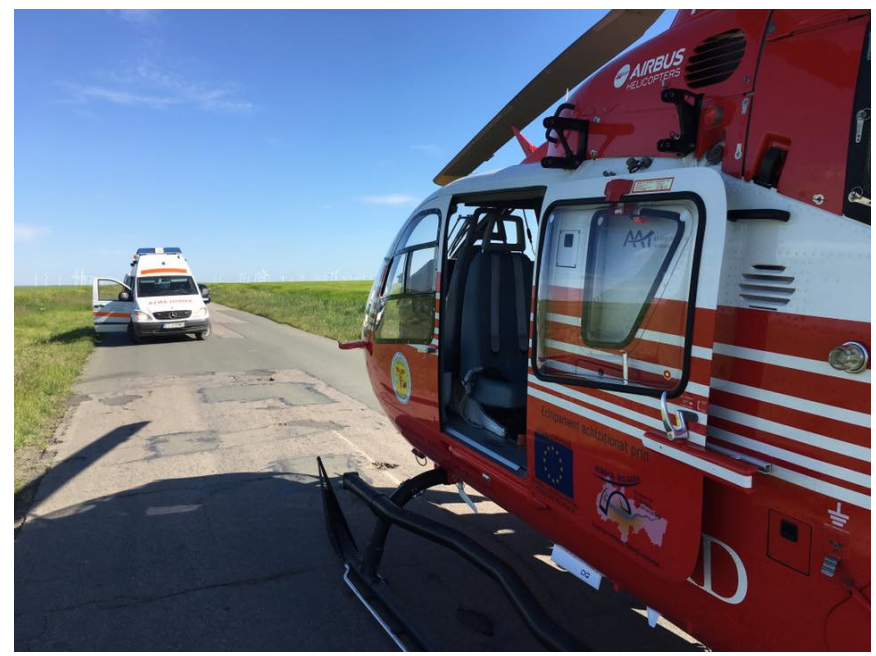

Fig. 5. Support provided by the SMURD helicopter to medical crews in the field for effective monitoring and disaster mitigation has been completed, with regard to the population within the borders of Romania, Ukraine and the Republic of Moldova "(Joint Operational Program Romania-Ukraine-Republic of Moldova). As a result, helicopters serving Iasi and Galati A.O.B. have performed so far several missions on the territory of the Republic of Moldova.

Continuous crew training is a priority. The training courses conducted in Romania by the Swiss Air Salvage Service specialists REGA, within the framework of the Swiss-Romanian Cooperation Program of Preparation, had three main components:

- NVIS - Night Vision Imaging System - Romanian flight instructors have strengthened their acquired knowledge so as to become trainers for other pilots. The training was supervised by REGA flight instructors.

- The use of the winch - Romanian pilots and doctors had the opportunity to develop new skills in case of special situations that can be encountered during the interventions and how these interventions are influenced by weather conditions, visibility or different obstacles.

- Simulator training - Pilots participated in standard and emergency procedures on the Swiss Air Force Base in Emmen.

As a result of the analysis of Table 1, there is a dynamic increase in the number of air missions in Romania, most of them being carried out by the air rescue bases from Târgu Mureş and Bucharest. When analyzing the data, we also need to take into account the following:

-The SMURD Galaţi Airbase became operational from 20th of June 2014;

-From the 15th of December 2014 until 31st of July 2015 the SMURD Airbase in Constanţa was inoperative;

-From the 2nd of June 2016 until 17th of January 2017, the Iasi SMURD Airbase was not operational;

It is also desirable to arrange landing grounds - heliports in the vicinity of hospitals. At this very moment, few hospital units have their own landing space (Figure 6).

Helicopter Emergency Medical Services (HEMS) are used worldwide in order to provide potentially life-saving pre-hospital medical support to trauma patients at the accident scene. The literature has clearly demonstrated the positive impact on the survival of critical patients assisted by aircrew, so it is necessary to further develop the air res-

Table 1. Number of aeromedical interventions

\begin{tabular}{lcccc}
\hline Location & 2013 & 2014 & 2015 & 2016 \\
\hline Târgu Mureș & 361 & 656 & 760 & 746 \\
București & 514 & 534 & 753 & 719 \\
lași & 335 & 415 & 561 & 276 \\
Arad & 248 & 401 & 436 & 451 \\
Craiova & 286 & 317 & 550 & 539 \\
Constanța & 107 & 286 & 142 & 378 \\
Galați & - & 104 & 340 & 551 \\
Total primary and secondary missions & 1851 & 2713 & 3542 & 3660 \\
\hline
\end{tabular}




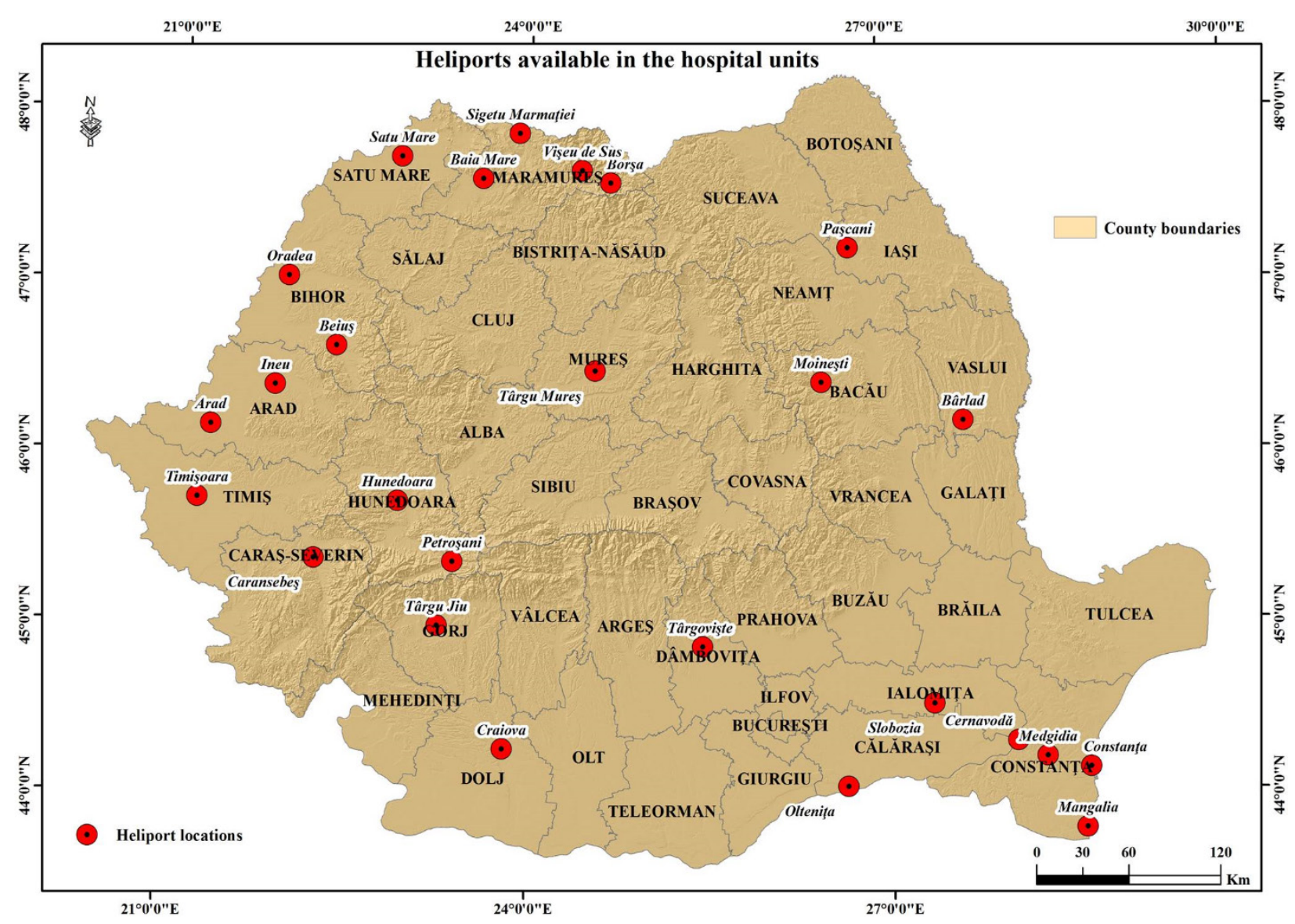

Fig. 6. Cities with medical units that own land helipads

cue system in Romania in the future [16]. It is necessary to increase the number of air bases, increasing the level of training of both pilots and the medical team. It would also be desirable to equip the helicopter with the possibility of blood transfusions in the event of severe haemorrhagic shocks. In the future, it is also desirable to implement the endovascular balloon occlusion of the aorta (REBOA).

\section{Conflicts of interest}

None

\section{References}

1. Andruszkow H, Lefering R, Frink M , et al. - Survival benefit of helicopter emergency medical services compared to ground emergency medical services in traumatized patients. Crit Care. 2013;17:R124.

2. Sturm JA, Pape HC, Dienstknecht T - Trauma care in Germany: an inclusive system. Clin Orthop Relat Res. 2013;471:2912-2923.

3. Andruszkow H, Frink M, Zeckey C, Krettek C, Hildebrand F, Mommsen $P$ - Merits and capabilities of helicopter emergency medical service (HEMS) in traumatized patients. Technol Health Care. 2012;20:435444

4. Galvagno Jr SM, Haut ER, Zafar SN et al. - Association between helicopter vs ground emergency medical services and survival for adults with major trauma. JAMA. 2012;307:1602-1610.

5. Galvagno Jr SM, Thomas S, Stephens C et al.- Helicopter emergency medical services for adults with major trauma. Cochrane Database Syst
Rev. 2013;3:CD009228.

6. Taylor C, Jan S, Curtis K, et al. - The cost-effectiveness of physician staffed Helicopter Emergency Medical Service (HEMS) transport to a major trauma centre in NSW, Australia. Injury. 2012;43:1843-1849.

7. Westhoff J, Hildebrand F, Grotz M, Richter M, Pape HC, Krettek C. Trauma care in Germany. Injury. 2003;34:674-683.

8. Butler DP, Anwar I, Willett K. - Is it the H or the EMS in HEMS that has an impact on trauma patient mortality? A systematic review of the evidence. Emerg Med J. 2010;27:692-701.

9. Biewener A, Aschenbrenner U, Rammelt S, Grass R, Zwipp H. - Impact of helicopter transport and hospital level on mortality of polytrauma patients. J Trauma. 2004;56:94-98.

10. Andruszkow $\mathrm{H}$, Hildebrand F, Lefering $\mathrm{R}$ Et al. - Ten years of helicopter emergency medical services in Germany: Do we still need the helicopter rescue in multiple traumatised patients? Injury. 2014;45:S53-S58.

11. Arhiva Istoric [Internet]. SMURD. [cited 2018Jan8]. Available from: http://smurd.ro/category/despre/istoric/

12. Taubenböck S, Lederer W, Kaufmann M, et al. - HEMS in alpine rescue for pediatric emergencies. Wilderness \& environmental medicine. 2016:27:409-414

13. Andruszkow $\mathrm{H}$, Lefering $\mathrm{R}$, Frink $\mathrm{M}$, et al. - Survival benefit of helicopter emergency medical services compared to ground emergency medical services in traumatized patients. Critical Care 2013;17:R124.

14. Schweigkofler U, Reimertz C, Lefering R, Hoffmann R. - Importance of air ambulances for the care of the severely injured. Der Unfallchirurg. 2015;118:240-244.

15. Droogh JM, Smit M, Absalom AR, Ligtenberg JJ, Zijlstra JG. Transferring the critically ill patient: are we there yet? Critical Care. 2015;19:62.

16. Ringburg AN, Thomas SH, Steyerberg EW, van Lieshout EM, Patka P, Schipper IB.- Lives saved by helicopter emergency medical services: an overview of literature. Air medical journal. 2009;28:298-302. 